\title{
Post-intravitreal injection endophthalmitis secondary to Turicella otitidis: a case report
}

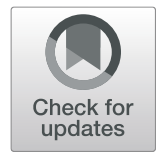

Danny A. Mammo ${ }^{1}$, Daniel Watson ${ }^{1}$ and Karen R. Armbrust ${ }^{1,2^{*}}$

\begin{abstract}
Background: Endophthalmitis is a rare but potentially devastating complication of intravitreal injection. The causative organism plays an important role in prognosis following endophthalmitis. Here we present the first reported case of Turicella otitidis endophthalmitis, which is notable for a delayed presentation.

Case presentation: A 71 year old male who was receiving intravitreal aflibercept injections for neovascular age-related macular degeneration presented 4 weeks after his most recent intravitreal injection and was found to have endophthalmitis. Polymerase chain reaction (PCR) testing of aqueous fluid was positive for Turicella otitidis. The endophthalmitis responded well to treatment with intravitreal antibiotics.

Conclusions: Coryneform bacteria are a rare cause of endophthalmitis, and this is the first reported case of endophthalmitis caused by the corynebacterium species Turicella otitidis. As in this case, post-intravitreal injection endophthalmitis may have a bacterial etiology even with delayed presentation. The relatively indolent disease course and excellent response to intravitreal antibiotics is consistent with previous ophthalmic reports regarding other corynebacteria, as well as with otolaryngology and hematology oncology reports addressing Turicella otitidis specifically. This case supports the growing body of evidence for pathogenicity of Turicella otitidis and demonstrates the utility of PCR for diagnosis in small volume aqueous specimens.
\end{abstract}

Keywords: Endophthalmitis, Anti-VEGF, Aflibercept, Turicella otitidis, Case report

\section{Background}

Intravitreal anti-vascular endothelial growth factor (VEGF) agents have transformed care for many vitreoretinal disorders, allowing visual improvement or stability in diseases with previously poor visual outcomes, such as age-related macular degeneration (AMD) with associated choroidal neovascularization $(\mathrm{CNV})$. However, endophthalmitis remains a rare but potentially devastating complication of anti-VEGF intravitreal injection, with rates of post-injection endophthalmitis ranging from 1 case in 1000 to 1 in 6450 [1-4]. The majority of culture-positive endophthalmitis cases are

\footnotetext{
* Correspondence: karen.armbrust@va.gov

'Department of Ophthalmology and Visual Neurosciences, University of Minnesota, 420 Delaware Street Southeast, MMC 493, Minneapolis, MN 55455, USA

${ }^{2}$ Department of Ophthalmology, Veterans Affairs Health Care System, Minneapolis, MN, USA
}

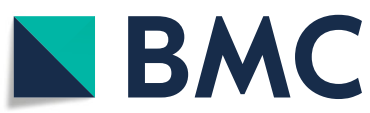

(C) The Author(s). 2020 Open Access This article is licensed under a Creative Commons Attribution 4.0 International License, which permits use, sharing, adaptation, distribution and reproduction in any medium or format, as long as you give appropriate credit to the original author(s) and the source, provide a link to the Creative Commons licence, and indicate if changes were made. The images or other third party material in this article are included in the article's Creative Commons licence, unless indicated otherwise in a credit line to the material. If material is not included in the article's Creative Commons licence and your intended use is not permitted by statutory regulation or exceeds the permitted use, you will need to obtain permission directly from the copyright holder. To view a copy of this licence, visit http://creativecommons.org/licenses/by/4.0/ The Creative Commons Public Domain Dedication waiver (http://creativecommons.org/publicdomain/zero/1.0/) applies to the data made available in this article, unless otherwise stated in a credit line to the data. coagulase-negative Staphylococcus species, which usually are associated with good outcomes. Poorer clinical outcomes have been reported in post-anti-VEGF endophthalmitis associated with other species, particularly in Streptococcus species. Corynebacterium, a genus of gram positive bacilli or coccobacilli, is a rare cause of post-procedural endophthalmitis [5-7]. Corynebacterium was found in only about $1 \%$ of the Endophthalmitis Vitrectomy Study culture positive endophthalmitis cases [8] and has only rarely been reported after anti-VEGF injection [2]. This is the first report of Corynebacterium species Turicella otitidis endophthalmitis following an ocular procedure. We review the patient's presentation, diagnosis, and response to treatment.

\section{Case presentation}

A 71 year old male with a history of exudative AMD status post 14 intravitreal aflibercept injections, right eye, 
and non-exudative AMD, left eye, presented to clinic for his scheduled intravitreal aflibercept injection. His most recent anti-VEGF treatment was 4 weeks prior to presentation. At presentation, the patient reported gradually worsening cloudy vision, new floaters, and photophobia right eye as well as a dull ache behind his right eye, managed with over the counter pain medication. On examination, his visual acuity, right eye, was $20 / 250$, decreased from his baseline of 20/60. Slit lamp examination of the right eye revealed conjunctival injection, confluent granulomatous keratic precipitates, grade 4+ anterior chamber cell, and grade $2+$ flare without fibrin. There was mild nuclear sclerosis in both eyes, symmetric between the two eyes. Dilated fundus exam showed vitreous haze without obvious retinitis in the right eye (Fig. 1a) and macular drusen left eye. B-scan ultrasonography of the right eye demonstrated scattered vitreous opacities with increased opacity concentration temporally, temporal chorioretinal thickening, and no retinal or choroidal detachment. Fluorescein angiography of the right eye was limited by poor image quality, but the focal area of hyperfluorescence in the temporal macula was more consistent with the preexisting choroidal neovascular membrane rather than an abscess.

Most patients with post-injection bacterial endophthalmitis present within 1 week of the causative injection [9, 10], so a broad differential diagnosis was entertained for this relatively indolent panuveitis. A bacterial exogenous endophthalmitis still was considered the most likely diagnosis, but blood cultures were drawn from 2 separate sites and serum testing for Quantiferon-Tb, rapid plasma reagin (RPR), fluorescent treponemal antibody absorption (FTA-Abs), Lyme enzyme immunoassay, Toxoplasma immunoglobulin $\mathrm{M}$ and immunoglobulin $\mathrm{G}$, angiotensin converting enzyme (ACE), and antineutrophil cytoplasmic antibodies (ANCA) was performed to rule out other causes of uveitis. The patient underwent treatment with empiric intravitreal vancomycin $(1 \mathrm{mg}$ in $0.1 \mathrm{ml})$ and ceftazidime $(2.25 \mathrm{mg}$ in $0.1 \mathrm{ml}$ ), and an aqueous specimen was sent for pan-bacterial (16S rRNA), pan-fungal (28S rDNA and ITS primer sets), and viral (HSV1, HSV2, VZV) polymerase chain reaction (PCR) analysis. Two days following intravitreal antibiotic injection, the aching eye pain subsided and vision started to slowly improve. Topical corticosteroids were added 3 days after the intravitreal antibiotic injection. One week after presentation, the aqueous pan-bacterial PCR result returned as positive for Turicella otitidis, with all other testing negative. Topical corticosteroids were slowly tapered as ocular inflammation improved. Four weeks after intravitreal antibiotic injection, the patient's visual acuity had returned to baseline and there was no ocular inflammation on twice daily prednisolone acetate $1 \%$ eye drops right eye (Fig. 1b).

\section{Discussion and conclusion}

Turicella otitidis is a non-fermenting Coryneform grampositive bacillus almost exclusively isolated from ear exudates and rarely found in skin flora [11]. Its pathogenicity in otitis media has been controversial, but Coryneform species are increasingly recognized as important pathogens in granulomatous mastitis [12], and Turicella otitidis specifically has been implicated as the causative agent in isolated cases of mastoiditis, cervical abscess, and bacteremia [13]. To our knowledge, this is the first reported case of Turicella otitidis endophthalmitis. The patient's presentation with granulomatous keratic precipitates is consistent with Turicella otitidis, since Coryneform species have been shown to survive in lipid-filled vacuoles surrounded by a reactive granulomatous infiltrate [12].

Turicella otitidis classically shows good susceptibility to ß-lactams, vancomycin and fluoroquinolones [11, 13]. Endophthalmitis due to Corynebacterium species in general has been shown to be susceptible to intravitreal vancomycin [6]. In this report, post-injection endophthalmitis secondary to Turicella otitidis appeared to be indolent in nature with a rapid response to empiric intravitreal vancomycin and ceftazidime. One interesting practical aspect of this case is the delay in presentation, consistent with the indolent nature of the organism. Although most bacterial endophthalmitis cases associated with intravitreal injections present within 1 week of the injection, the subject in this case did not present until 4 weeks after the injection. It is important to

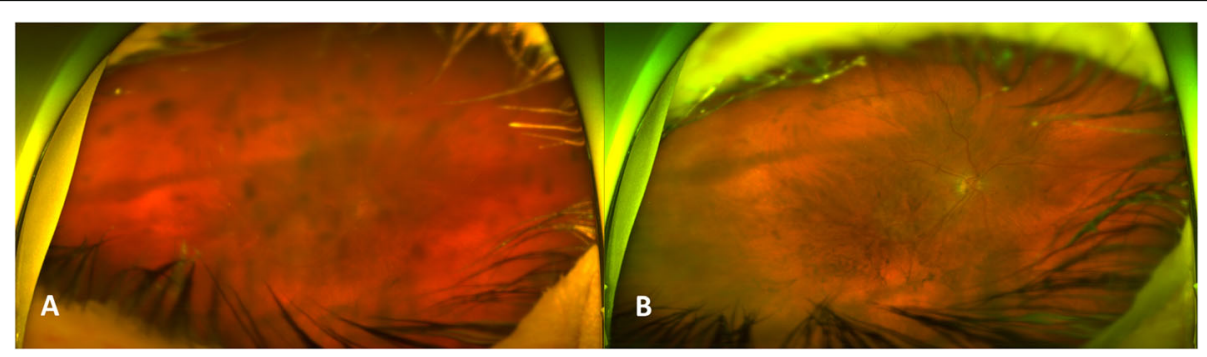

Fig. 1 Optos wide-field fundus imaging of the right eye a) at presentation showing dense vitreous debris and $\mathbf{b}) 4$ weeks after intravitreal antibiotics showing near resolution of the vitreous debris 
consider a bacterial etiology for post-intravitreal injection endophthalmitis even with a delay in presentation.

Prior work shows that blood culture and PCR have a higher diagnostic yield for endophthalmitis than conventional plate culture in vitreous specimens [14], and blood culture requires a larger volume specimen than PCR. Aqueous specimens typically are smaller in volume than vitreous specimens, but obtaining an aqueous specimen is technically easier than obtaining a vitreous specimen, and a diagnostic anterior chamber paracentesis may be less likely than a vitreous tap to cause an associated retinal detachment. Previous studies show that false positive rates for both aqueous and vitreous PCR are very low $[15,16]$, and also in this case the granulomatous uveitis and the rapid response to intravitreal antibiotics prior to corticosteroid treatment are confirmatory of the aqueous PCR result.

Pan-bacterial PCR detects whether bacteria-specific DNA encoding 16S ribosomal RNA is present in the specimen; if the $16 \mathrm{~S}$ ribosomal RNA gene is present, sequences within that gene are compared to DNA sequence databases to identify the specific bacterial organism [17, 18]. In most cases of presumed infectious endophthalmitis after intravitreal injection, routine cultures are used for organism identification. However, for this case with delayed presentation, because the differential diagnosis was broad, the aqueous specimen volume was insufficient for bacterial and fungal cultures as well as viral PCR. PCR of the aqueous fluid proved helpful by identifying Turicella otitidis as the causative organism while ruling out more sinister etiologies, such as a fungal endophthalmitis - which was considered given the indolent nature of the endophthalmitis - or a viral retinitis such as acute retinal necrosis unrelated to intravitreal injection. This report demonstrates the utility of PCR in identifying organisms in cases that are more likely to be culture negative, such as when a smaller volume aqueous specimen is obtained.

In summary, we present a case of post-intravitreal injection endophthalmitis that was determined to be bacterial despite the delayed presentation. The causative organism, Turicella otitidis, was diagnosed by aqueous pan-bacterial PCR, and the endophthalmitis showed an excellent response to intravitreal antibiotics.

\section{Abbreviations}

AMD: Age-related macular degeneration; CNV: Choroidal neovascularization; PCR: Polymerase chain reaction; VEGF: Vascular endothelial growth factor

\section{Acknowledgements}

Not applicable.

\section{Other sections}

Financial Disclosures: Funding was provided by the University of Minnesota ophthalmology teaching and research fund. The funding body had no role in study design, data analysis, data interpretation, or manuscript writing.
This material is the result of work supported in part with resources and the use of facilities at the Minneapolis Veterans Affairs Health Care System. The contents of this manuscript do not represent the views of the U.S.

Department of Veterans Affairs or the USA Government.

\section{Authors' contributions}

DM contributed to data acquisition, data analysis, manuscript drafting, and manuscript revision. DW contributed to data acquisition and manuscript revision. KA contributed to study design, manuscript drafting, and manuscript revision. All authors read and approved the final manuscript.

\section{Funding}

Funding was provided by the University of Minnesota ophthalmology teaching and research fund. The funding body had no role in study design, data analysis, data interpretation, or manuscript writing.

\section{Availability of data and materials}

All data from the case has been included, including images. Any further material is available upon request.

Ethics approval and consent to participate

Ethics committee approval was not applicable.

Patient approval was obtained with a signed consent form.

\section{Consent for publication}

The patient provided written consent for publication of the patient data and accompanying images in this case report.

\section{Competing interests}

The authors declare that they have no competing interest.

Received: 16 October 2019 Accepted: 30 March 2020

Published online: 10 April 2020

\section{References}

1. Fileta JB, Scott IU, Flynn HW. Meta-analysis of infectious endophthalmitis after intravitreal injection of anti-vascular endothelial growth factor agents. Ophthalmic Surg Lasers Imaging Retina. 2014;45(2):143-9.

2. Sachdeva MM, Moshiri A, Leder HA, Scott AW. Endophthalmitis following intravitreal injection of anti-VEGF agents: long-term outcomes and the identification of unusual micro-organisms. J Ophthalmic Inflamm Infect. 2016;6(1):2.

3. Xu K, Chin EK, Bennett SR, et al. Endophthalmitis after intravitreal injection of vascular endothelial growth factor inhibitors: management and visual outcomes. Ophthalmology. 2018;125(8):1279-86.

4. Stem MS, Rao P, Lee IJ, et al. Predictors of endophthalmitis after intravitreal injection. Ophthalmol Retina. 2018;3(1):3-7.

5. Joseph J, Nirmalkar K, Mathai A, Sharma S. Clinical features, microbiological profile and treatment outcome of patients with Corynebacterium endophthalmitis: review of a decade from a tertiary eye care centre in southern India. Br J Ophthalmol. 2016;100(2):189-94.

6. Kuriyan AE, Sridhar J, Flynn HW, et al. Endophthalmitis caused by species: clinical features, antibiotic susceptibility, and treatment outcomes. Ophthalmol Retina. 2017;1(3):200-5.

7. Bhattacharjee $H$, Bhattacharjee $K$, Gogoi K, Singh M, Singla BG, Yadav A. Microbial profile of the vitreous aspirates in culture proven exogenous endophthalmitis: a 10-year retrospective study. Indian J Med Microbiol. 2016;34(2):153-8.

8. Han DP, Wisniewski SR, Wilson LA et al. Spectrum and susceptibilities of microbiologic isolates in the Endophthalmitis Vitrectomy Study. Am J Ophthalmol. 1996;122(1):1-17.

9. Shah CP, Garg SJ, Vander JF, et al. Outcomes and risk factors associated with endophthalmitis after intravitreal injection of anti-vascular endothelial growth factor agents. Ophthalmology. 2011;118(10):2028-34

10. Yannuzzi NA, Gregori NZ, Rosenfeld PJ, et al. Endophthalmitis associated with intravitreal injections of anti-VEGF agents at a tertiary referral center: inhouse and referred cases. Ophthalmic Surg Lasers Imaging Retina. 2018; 49(5):313-9.

11. Gomez-Garces JL, Alhambra A, Alos Jl, Barrera B, García G. Acute and chronic otitis media and Turicella otitidis: a controversial association. Clin Microbiol Infect. 2004;10(9):854-7. 
12. Dobinson HC, Anderson TP, Chambers ST, Doogue MP, Seaward L, Werno AM. Antimicrobial treatment options for granulomatous mastitis caused by Corynebacterium species. J Clin Microbiol. 2015;53(9):2895-9.

13. Loïez C, Wallet F, Fruchart A, Husson MO, Courcol RJ. Turicella otitidis in a bacteremic child with acute lymphoblastic leukemia. Clin Microbiol Infect. 2002;8(11):758-9.

14. Pongsachareonnont P, Honglertnapakul W, Chatsuwan T. Comparison of methods for identifying causative bacterial microorganisms in presumed acute endophthalmitis: conventional culture, blood culture, and PCR. BMC Infect Dis. 2017;17(1):165.

15. Chiquet C, Cornut PL, Benito Y, et al. Eubacterial PCR for bacterial detection and identification in 100 acute postcataract surgery endophthalmitis. Invest Ophthalmol Vis Sci. 2008;49(5):1971-8.

16. Harper TW, Miller D, Schiffman JC, Davis JL. Polymerase chain reaction analysis of aqueous and vitreous specimens in the diagnosis of posterior segment infectious uveitis. Am J Ophthalmol. 2009;147(1):140-147.e2.

17. Sugita S, Shimizu N, Watanabe $K$, et al. Diagnosis of bacterial endophthalmitis by broad-range quantitative PCR. Br J Ophthalmol. 2011;95:345-9.

18. Kosacki J, Boisset $S$, Maurin M, et al. Specific PCR and quantitative real-time PCR in ocular samples from acute and delayed-onset postoperative endophthalmitis. Am J Ophthalmol. 2020;212:34-42.

\section{Publisher's Note}

Springer Nature remains neutral with regard to jurisdictional claims in published maps and institutional affiliations.

Ready to submit your research? Choose BMC and benefit from:

- fast, convenient online submission

- thorough peer review by experienced researchers in your field

- rapid publication on acceptance

- support for research data, including large and complex data types

- gold Open Access which fosters wider collaboration and increased citations

- maximum visibility for your research: over $100 \mathrm{M}$ website views per year

At BMC, research is always in progress.

Learn more biomedcentral.com/submissions 